\title{
CONSUMIDORES DO RAMO DE JOALHERIA: COMPORTAMENTO E FERRAMENTAS DE MARKETING PARA FIDELIZAÇÃO
}

\author{
Thais Rubia Ferreira Lepre, Maria Fernanda Bernardes Petenati \\ Universidade do Oeste Paulista - UNOESTE, Presidente Prudente, SP. E-mail: thaisrubia@unoeste.br
}

\begin{abstract}
RESUMO
As mudanças ocorridas no ambiente mercadológico, acarretadas principalmente pelo massivo aumento da competitividade, trouxeram novas demandas para as organizações que precisam compreender o que o seu consumidor necessita e/ou deseja para conquista-lo, em meio a diversidade de opções disponíveis. Necessidade esta que está presente em qualquer tipo de negócio, independente do segmento, inclusive nas Joalherias, segmento que é objeto deste estudo. Diante disso, para conquistar e fidelizar os clientes é preciso utilizar artifícios, e as ferramentas de marketing tem sido vistas como fundamentais para este fim. No entanto, diante da diversidade de ferramentas existentes, o desafio dos gestores do segmento de joalherias, é saber quais devem ser utilizadas. Justificando a existência deste artigo que visa discutir tal questão, beneficiando a todos os gestores de joalherias, considerando que tem como objetivo identificar o comportamento de compra de consumidores do segmento de joalheria e as ferramentas que esse tipo de negócio pode utilizar para fidelizar seus clientes. Para tanto, possui uma abordagem qualitativa, tendo a pesquisa bibliográfica com instrumento de coleta de dados e a analise destes por meio da técnica de analise de conteúdo. É possível concluir que os consumidores deste segmento apresentam características peculiares com relação ao seu comportamento de compra, e que a pesquisa de mercado, o endomarketing, o CRM, o pós-venda e o programa de fidelidade, são as ferramentas de marketing mais adequadas para fidelização deste público.
\end{abstract}

Palavras-chave: Comportamento do Consumidor. Joalheria. Fidelização. Ferramentas de Marketing.

\section{CONSUMERS IN THE JEWELRY INDUSTRY: MARKETING BEHAVIOR AND TOOLS FOR LOYALTY}

\begin{abstract}
The changes in the market environment, caused mainly by the massive increase in competitiveness, have brought new demands to organizations that need to understand what their consumers need and / or want to achieve, amidst the diversity of available options. This need is present in any type of business, regardless of the segment, including in the Jewelers segment, which is the subject of this study. Faced with this, to win and retain customers is to use artifice, and marketing tools have been seen as fundamental for this purpose. However, given the diversity of existing tools, the challenge for managers of the jewelery segment is to know which ones should be used. Justifying the existence of this article that aims to discuss this issue, benefiting all the managers of jewelry, considering that its objective is to identify the buying behavior of consumers in the jewelry segment and the tools that this type of business can use to retain their customers. To do so, it has a qualitative approach, having the bibliographic research with an instrument of data collection and the analysis of these through the technique of content analysis. It is possible to conclude that consumers in this segment have characteristics peculiar to their buying behavior, and that market research, endomarketing, CRM, after-sales and loyalty program are the most appropriate marketing tools for Loyalty of this public.
\end{abstract}

Keywords: Consumer Behavior. Jewelry. Loyalty. Marketing Tools.

\section{INTRODUÇÃO}

O aumento da competitividade tem gerado novas demandas as empresas, pois os consumidores do século XXI, diferente do que ocorria no século passado, tem uma diversidade de opções a sua disposição, e com isso vem 
tornando-se cada dia mais exigentes e seletivos. Então, conquistar o público pretendido tem exigido das empresas novos esforços, entre eles, destaca-se a necessidade de compreender o que o seu consumidor necessita e/ou deseja.

Desta forma, faz-se necessário estudar seu comportamento, e esta necessidade se aplica a empresas de qualquer segmento, tendo em vista que, o tipo de produto/serviço comercializado atrai pessoas de idades, classes, hábitos, estilos de vida diferentes, que apresentam comportamentos variados, pois, o comportamento muda de acordo com a classificação dos produtos, que podem ser enquadrados em: bens duráveis, bens não duráveis e serviços.

Assim cada uma dessas classes de produtos exige do consumidor decisões que refletem em maior ou menor grau na sua vida, principalmente os bens duráveis, por geralmente, demandarem maior dispêndio de recursos. Considerando que compreende segmentos como o de Joalherias, foco deste artigo, e que assim como as demais categorias de empresas busca a fidelização de clientes, com uma dificuldade maior para alcança-la, considerando o alto valor das peças comercializadas.

E para alcançar esta fidelização, as organizações podem utilizar alguns artifícios, sendo as ferramentas de Marketing consideradas entre as principais aliadas para este fim, no entanto diante da diversidade de opções existentes, o desafio dos gestores do segmento de joalherias, é saber quais ferramentas devem ser utilizadas.

Justificando a existência deste artigo que visa discutir tal questão, beneficiando a todos os gestores de joalherias, considerando que tem como problemática: qual é o comportamento de compra de consumidores do segmento de joalheria? Quais ferramentas de marketing esse tipo de negócio pode utilizar para fidelização dos clientes?

Diante disso, o objetivo geral deste estudo consiste em identificar o comportamento de compra de consumidores do segmento de joalheria e ferramentas de marketing que esse tipo de negócio pode utilizar para fidelização dos clientes. E os objetivos específicos recaem em: caracterizar o segmento de joalheria; identificar o comportamento dos consumidores desse tipo de negócio; levantar as ferramentas de marketing que podem ser utilizadas para fidelização desse tipo de publico.
Acredita-se que o comportamento de compra dos consumidores do segmento de joalherias está relacionado com os fatores cultural, social, pessoal e psicológico, e que as empresas de um modo geral se utilizam de recursos de marketing para satisfazer as vontades dos seus clientes a fim de fidelizá-los. Supõe-se que algumas das ferramentas que as joalherias podem utilizar para fidelizar os clientes é realizar ações que contribuam para motivação dos funcionários (visando qualidade no atendimento), e criar programas de fidelidade.

\section{MÉTODOS}

Considerando que a metodologia direciona as etapas a serem realizadas para viabilização de qualquer trabalho científico, o presente artigo contou com uma abordagem qualitativa, tendo a pesquisa bibliográfica como único instrumento de coleta de dados e análise de conteúdo, como técnica de analise destes. Nos parágrafos seguintes tem-se a descrição mais detalhada destes métodos e de sua utilização no presente artigo.

Iniciando pela abordagem qualitativa, segundo Mascarenhas (2012, p. 46)

Utilizamos a pesquisa
qualitativa quando
queremos descrever nosso
objeto de estudo com
mais profundidade. Por
isso, ela é muito comum
em estudos sobre o
comportamento de um
indivíduo ou de um grupo
social. [...] Suas principais
características são: os
dados são levantados e
analisados ao mesmo
tempo; os estudos são
descritivos, voltados para
a compreensão do objeto;
a influência do
pesquisador sobre a
pesquisa não é evitada;
muito pelo contrario, é
considerada fundamental

Nesta abordagem, o que importa é o que foi dito e qual sua relevância para o tema, em que os aspectos encontrados em diferentes documentos e referências, são relacionados, para conseguir responder aos questionamentos levantados durante o estudo, justificando sua escolha para esta pesquisa, que buscou compreender através da interpretação das 
informações coletadas, o comportamento dos consumidores do segmento de joalherias e as ferramentas de marketing mais adequadas para sua fidelização.

E para tanto, contou com a pesquisa bibliográfica para coletar todas as informações necessárias, tendo em vista que de acordo com Gil (2010, p. 29) “a pesquisa bibliográfica é elaborada com base em material já publicado. Tradicionalmente, esta modalidade de pesquisa inclui material impresso, como livros, revistas, jornais, teses, dissertações e anais de eventos científicos". Que foi viabilizada através de livros, artigos científicos e sites.

E como forma de analisar os dados recolhidos, aplicou-se a análise de conteúdo, por esta técnica permitir "[...] caminhar na descoberta do que está por trás dos conteúdos manifestos, indo além das aparências do que está sendo comunicado" (GOMES, 2007, p. 84). Como foi realizado neste estudo, que buscou compreender detalhadamente os conteúdos disponíveis nas citações e ideias manifestas pelos autores utilizados.

\section{RESULTADOS}

Nesta seção consta toda fundamentação teórica deste estudo, realizada a partir de materiais já publicados.

\subsection{Definição do Comportamento do Consumidor e seu processo de compra}

Para melhorar o atendimento e satisfazer os clientes, as empresas precisam desvendar seu comportamento, pois desta forma, poderão detectar quais carências e necessidades o consumidor possui, a fim de traçar as melhores estratégias para satisfazê-lo.

De acordo com Limeira (2008, p. 4) "estudar o comportamento do consumidor brasileiro é pensar sobre como vivemos, como nos relacionamos com nossa família e com nossos amigos, como fazemos escolhas e tomamos decisões no dia-a-dia."

Estudar o comportamento do consumidor é compreender a pessoa em seu papel de cliente, saber quais suas necessidades e quais produtos adquirem, desta forma, conhecendo seus consumidores a empresa consegue planejar e projetar seus planos de marketing e decidir se deverão promover determinado produto em primeiro plano, ao invés de um outro produto (SHETH; MITTAL; NEWMAN, 2011).
Para Paixão (2012, p. 20) "estudar o comportamento do consumidor é importante para o marketing. É por meio de tal estudo que as empresas percebem oportunidades para satisfazer às necessidades de seus clientes".

Assim, faz-se necessário as empresas adquirirem tal conhecimento, conseguir tipificar o comportamento de seu consumidor, bem como as preferências de modelo/cor de determinado produto, sem que haja desperdício de tempo e dinheiro com produtos que seus consumidores não comprarão.

O comportamento do consumidor pode ser entendido como "interação dinâmica entre afeto e cognição, comportamento e ambiente por meio da qual os seres humanos conduzem na vida atitudes relacionadas à troca" (PETER; OLSON, 2010, p. 5). Isto é, são etapas que precedem a compra, envolvendo os pensamentos, sentimentos, emoções, procedimentos e vontades do consumidor. Essa relação é dinâmica, ou seja, pode sofrer alterações a qualquer momento na realização e efetivação da compra do produto desejado.

Para Samara e Morsch (2005, p. 2):

O comportamento do consumidor se caracteriza como processo: um conjunto de estágios que envolve a seleção, a compra, o uso ou a disposição de produtos, idéias ou experiências para satisfazer necessidades e desejos. [...] E esse processo é contínuo, não se limitando apenas ao momento de compra [...].

Ou seja, mesmo antes de comprar determinado produto, o consumidor estuda, pesquisa e interage com seus pares para definir a opção que irá satisfazer com mais eficiência sua necessidade. Algumas vezes esse estágio não é algo único e sim contínuo ou seja, são processos até que leve o consumidor a efetuar a compra.

Como forma de estudo do comportamento dos consumidores, foram determinados alguns fatores que influenciam na decisão de compra. Segundo Kotler (2000, p. 183) "o comportamento de compra do consumidor é influenciado por fatores culturais, sociais, pessoais e psicológicos. Os fatores 
culturais exercem a maior e mais profunda influencia".

Desta forma as empresas começam a estudar melhor e entender o pensamento de seu consumidor afim de satisfazê-lo e fideliza-lo.

Iniciando pelos fatores culturais que exercem muita influencia no comportamento de compra das pessoas e também nos desejos pois, instigam os consumidores a consumir determinado produto por se tratar de algo cultural de sua região ou família. Esta cultura é adquirida desde criança e vai se aprimorando conforme a idade aumenta tudo que se aprende é transmitido de geração para geração incluindo normas, moral, ideias, conhecimento, habilidades e valores.

Conforme confirma, Kotler e Keller (2006, p.173):

Cultura, subcultura e
classe social são fatores
particularmente
importantes no
comportamento de
compra. A cultura é a
principal determinante do
comportamento e dos
desejos de uma pessoa. À
medida que cresce, a
criança absorve certos
valores, percepções,
preferências e
comportamentos de sua
família e de outras
instituições.

Esse fator cultural é dividido em subcultura que pode ser entendida como grupos de uma determinada cultura, que possuem características similares de comportamento e se unem para melhor distinção. Pode-se dividir a partir da idade, religião, raça, níveis de renda, nacionalidade entre outras e essas informações alimentam a formação de cultura de um determinado grupo (SAMARA; MORSCH, 2005).

Já a classe social são divisões da sociedade que podem ser ou não homogêneas e duradouras, nesta classe encontra-se pessoas que possuem semelhanças de comportamento por isso criam-se classes sociais por questão de afinidade (KOTLER, 2000).

Este fator social é composto por grupos de referência familiar, papel social e status, onde de acordo com Paixão (2012, p. 56) "os fatores sociais determinam a condição social do consumidor". Nesse fator em específico os grupos podem ser divididos em primários família - e secundário - grupos religiosos - e está ligado diretamente com o local onde se vive e possui certa influência na decisão de compra, assim como o fator pessoal exerce.

Kotler e Keller (2006, p. 179) fundamentam que "as decisões do comprador também são influenciadas por características pessoais, como idade e estágio no ciclo da vida, ocupação, circunstancias econômicas, personalidade, auto-imagem, estilo de vida e valores". Os padrões de consumo são moldados de acordo com o clico do indivíduo, levando em consideração a idade, sexo e tamanho do grupo familiar, isso faz com que os profissionais de marketing consigam atingir seus objetivos com mais eficiência.

A compreensão do comportamento humano pode ser analisada e estudada através de uma análise de suas necessidades, onde se denomina como o fator psicológico em que essas atitudes fazem os consumidores escolher determinado produto ao invés de outro, são de origem psicológica e social por isso dão essas opções que são na maioria das vezes inconscientemente na hora da compra.

De acordo com Kotler e Keller (2006, p. 182) "um conjunto de fatores psicológicos combinado a determinadas características do consumidor leva a processos de decisão e decisões de compra". Esse conjunto faz com que a pessoa compre determinado produto por uma questão de desejo e não de necessidade, isso está geralmente ligado a motivação que a pessoa tem.

Além desses fatores gerais existem também fatores específicos de acordo com o segmento da empresa, pois deve-se considerar o comportamento do consumidor em diferentes segmentos de mercado, caso isso não ocorra, há um risco eminente de generalizar todos os segmentos existentes. $E$, assim não determinar o comportamento do consumidor de determinado grupo (MERLO, 2014).

Assim, é necessário classificar o comportamento do consumidor para cada segmento de negócio, neste estudo trata-se de uma joalheria onde Honorato (2004) classifica na categoria de bens duráveis, pois seu ciclo de vida não possui prazo definido.

Com relação aos produtos adquiridos pelos consumidores, Honorato (2004, p.175, grifo do autor) classificou como: 


\begin{abstract}
bens de consumo [...]. Os bens de consumo são classificados de acordo com os hábitos de compra dos consumidores, que têm conseqüencias diretas na definição das estratégias de marketing. [...] existem quatro categorias de bens, a saber: bens de compra comparada, bens de conveniência, bens específicos ou especialidades, bens não procurados ou não previstos.
\end{abstract}

Bens de conveniência são bens que o consumidor adquire sem que haja qualquer tipo de esforço, sua compra é frequente e o consumidor não possui interação de compra. Bens de compra comparada exigem do consumidor certo esforço para efetivar sua compra pois ele compara produtos similares para decidir qual opção irá satisfazer melhor suas necessidades e os bens não procurados são aqueles produtos que o consumidor não possui tanto interesse e dessa maneira não consome com facilidade e de maneira corriqueira.

Já os bens específicos "são itens, [...] que o consumidor faz um esforço especial para procurar e comprar" (KERIN et. al., 2011, p. 279). Neste tipo de bem, o ramo de joalheria em estudo se enquadra pois se trata de um produto relativamente único e desenvolvido apenas para aquela determinada pessoa. Por se tratar de produtos de luxo, o consumidor acaba buscando mais informações antes de sua decisão de compra, automaticamente quando realizam se tornam cada vez mais fiéis à marca e/ou a loja.

Segundo Passarelli (2010) existem alguns elementos essenciais encontrados nos produtos de luxo, entre eles pode-se destacar a qualidade pois é inadimissível que um produto luxuoso tenha algum tipo de erro de fabricação problemas com acabamento, desconformidade de projeto - a utilização de materiais nobres, preço superior e escassez, são outros elementos desse bem.

Já para os autores Lipovetsky e Roux (2005, p. 127):

um produto de luxo é um conjunto: um objeto (produto ou serviço), mais um conjunto de representações: imagens, conceitos, sensações, que são associadas a ele pelo consumidor, e, portanto, que o consumidor compra com o objeto e pelos quais está disposto a pagar um preço superior ao que aceitaria pagar por um objeto de caracteristicas funcionais equivalentes, mas sem essas representações associadas.

Os consumidores desse tipo de bem de luxo possuem características mais evidentes que são "ciclo de vida, gênero, constituição da família, papel social, classe de renda, ocupação, posição social e fatores psicossociais, e em todos os casos se orientam pelos valores hedônio e simbólico. Os principais consumidores de jóias são pessoas dos 30 aos 70 anos" (ROCHA, 2009, p. 143).

Neste tipo de ramo, a joalheria consegue abranger clientes com uma faixa etária maior, onde na maioria das vezes, são consumidores que possuem renda elevada e conseguem pagar e satisfazer seu desejo de adquir determinada jóia.

\subsection{Classificação de Produtos}

No mundo mercadológico, empresas necessitam classificar os produtos a fim de identificar o ciclo de vida de cada bem e/ou serviço, com isso se torna uma vantagem competitiva pois antes mesmo do produto chegar ao seu máximo de utilização, a empresa consegue suprir a necessidade do cliente, sem que ele precise expor seu pensamento ou vontade.

"Os produtos podem ser classificados de diversas maneiras, tradicionalmente as empresas tomam como base as características: durabilidade, tangibilidade e utilidade - bens de consumo - $e$ empresarial ou industrial". (BENNETT 1995 apud HONORATO, 2004, p. 174, grifo do autor)

Por conta do tempo de vida útil, pode-se dividir e classificar os produtos em bens duráveis e não duráveis e também serviços. 
Quadro 1. Classificação bens duráveis, não duráveis e serviços

\begin{tabular}{|l|l|l|}
\hline CLASSIFICAÇÃO & \multicolumn{1}{|c|}{ DESCRIÇĀO } & \multicolumn{1}{c|}{ EXEMPLO } \\
\hline Bens duráveis & $\begin{array}{l}\text { São produtos tangiveis que } \\
\text { normalmente sobrevivem por } \\
\text { um longo periodo de tempo. }\end{array}$ & $\begin{array}{l}\text { Fogão, geladeira, máqui- } \\
\text { na de lavar, automóvel, } \\
\text { vestuário. }\end{array}$ \\
\hline $\begin{array}{l}\text { Bens nāo } \\
\text { duráveis }\end{array}$ & $\begin{array}{l}\text { São também produtos tan- } \\
\text { giveis que quase sempre se } \\
\text { prestam a poucas utilizaçōes. }\end{array}$ & $\begin{array}{l}\text { Sabonete, creme dental, } \\
\text { enlatado, perfume, } \\
\text { cerveja. }\end{array}$ \\
\hline Serviços & $\begin{array}{l}\text { São atividades ou beneficios } \\
\text { intangiveis e de consumo } \\
\text { rápido. }\end{array}$ & $\begin{array}{l}\text { Viagem, conserto de } \\
\text { eletrodoméstico, consulta } \\
\text { médica, odontológica. }\end{array}$ \\
\hline
\end{tabular}

Fonte: Honorato (2004, p. 174)

Bens duráveis pode-se compreender em produtos que o consumidor final consegue palpar, possuem um ciclo de vida maior, sendo que não há um prazo determinado para troca do bem. Já os bens não duráveis entende-se como produtos que não possuem uma vida util longa pois sua deteriorização é rapida, assim fazendo com que haja necessidade de troca do bem para continuar satisfazendo o desejo do consumidor. Os serviços são algo que não pode-se palpar, ou seja, não transforma objetos em bens, porém seu consumo ocorre enquanto é prestado.

Dessa maneira o segmento de joalherias, em que enquadra-se a empresa em estudo encontra-se no ramo de bens duráveis pois seus produtos apresentam ciclo de vida util elevado fazendo com que o consumidor não precise trocar o bem por conta de uma deteriorização.

Os bens duráveis do segmento de joalherias podem ser entendidos como algo de luxo onde Castaréde (2005) define que um objeto de luxo deve apresentar uma característica personalizada, tentar ser o mais perfeito possível, esteticamente belo e na maioria das vezes raro. Por conta dessa raridade, exclusividade justificase o diferencial do preço, sendo mais elevado do que os demais produtos.

Já para Galhanone (2005) o termo "luxo" é ligado exclusivamente a tudo que é raro, exclusivo e desenvolvido na maioria das vezes para aquele determinado consumidor, assim também elevando os custos para adquiri-los.

Assim, os objetos determinados luxuosos são desejos de todas as pessoas porém acessível apenas para alguns pois sua maior característica é ser exclusivo e único.

Segundo Strehlau (2004) o produto pode ser determinado como bem de consumo luxuoso por conta de três aspectos principais: por ser composto de matéria prima rara, de boa reputação e ter tecnologia especial para desenvolver aquele bem.

O segmento de joalherias, trabalha com diversos materiais porém o seu foco principal se dá em jóias onde o autor Straliotto (2009, p.28, grifo do autor) define "como sendo um objeto, usado junto ao corpo, que contempla ou ressalta esteticamente a aparência de quem o usa, isto é, um adorno corporal feito com materiais naturais raros, em geral materiais nobres"

A quem usa esses objetos, se sente melhor aparentemente por causar uma satisfação momentânea e isso faz com que continue comprando e utilizando esses artefatos, uma maneira que fideliza os seus consumidores.

Neste segmento joalheiro é possível ser encontrado "características únicas, possibilitando ao designer desenvolver projetos singulares com design exclusivo." (GUILGEN; FERRO, p.142, 2015). Com essas informações, cada peça projetada e realizada é única para aquele tipo de consumidor, assim, satisfazendo ainda mais seus desejos e vontades.

\subsection{Marketing e Fidelização de Clientes}

Historicamente é difícil identificar quando surgiu o marketing, mas tudo começou em meados do século XVIII, na Inglaterra, onde iniciou a revolução industrial, trazendo grande desenvolvimento na esfera econômica e social, contando com consideráveis mudanças nos procedimentos de produção. (KOTLER, 2005) Que passaram de processos artesanais para produção em massa, devido ao desenvolvimento dos meios de produção, elevando a quantidade de produtos ofertada ao mercado.

Diante disso, produzir apenas um produto de qualidade já não era o bastante para atender as exigências dos consumidores, que neste momento da história, começaram a ter opções. Conforme Las Casas (2006, p.6): 
Com a necessidade de vender excedentes de produtos que foram produzidos como resultado de produtividade maior e, conseqüentemente, aumentando $\mathrm{o}$ estoque das empresas, as vendas passaram a ser a atividade mais importante. A ordem era vender a qualquer custo.

Assim, a partir desse momento, as empresas começaram a se preocupar em divulgar seus produtos a fim de conseguir vender tudo que estava estocado. A partir de então, começa a surgir o termo "marketing".

Que de acordo com Yanaze, Makus e Carrilho $(2012$, p.5)

[...] é a concepção e o desenvolvimento de determinado bem ou serviço e a forma como eles são elaborados, distribuídos, precificados e comunicados. Marketing nada mais é do que o planejamento adequado para a inserção e a manutenção de um produto no mercado.

Em uma visão mais ampla, marketing pode ser entendido como uma ferramenta muito utilizada pelas empresas para que consigam atender as necessidades e desejos dos seus consumidores, em um curto prazo, assim, ganhando um diferencial diante da concorrência.

Kotler e Keller (2006, p.4) trazem outra visão de marketing onde entendem que: "envolve a identificação e a satisfação das necessidades humanas e sociais. [...] podemos dizer que ele 'supre necessidades humanas'”. Na concepção dos autores o marketing, auxilia as organizações na compreensão e atendimento das necessidades e desejos dos seus clientes, contribuindo para satisfação dos mesmos.

Já para American Marketing Associacion AMA (apud OGDEN; CRESCITELLI, 2007, p.1) marketing é a:

atividade organizacional e um conjunto de processos para criar, comunicar e entregar valor e gerenciar relacionamento com

clientes, mantendo

benefícios para a

organização e para seus públicos de interesse. Segundo essa definição, três fatores merecem destaque: 1) a entrega de valor em detrimento da oferta de produtos e serviços; 2) $\quad$ 2) relacionamento com clientes; e 3) a geração de benefícios não somente para a empresa e seus clientes, mas também para todos os públicos de interesse da empresa (os steakholders).

O marketing é uma dos recursos mais utilizados pelas organizações, porém, é importante que seu uso seja pautado na boa relação empresa-cliente, trazendo benefícios bilaterais: de um lado atendendo as vontades dos clientes e por outro lado obtendo simultaneamente lucro para o negócio.

Neste sentido, "a principal tarefa da função do marketing [...] não é manipular os consumidores para que façam o que atenda aos interesses da empresa, mas, sim, encontrar meios mais eficientes e eficazes que levem a empresa a fazer o que atende aos interesses dos consumidores." (PETER; DONNELY JR., 2013, p. 7) com a finalidade de fidelizá-los, tendo em vista que "manter um cliente é mais barato que conquistar um novo cliente" (PETROCCHI, 2007, p.59).

E a manutenção destes na empresa, depende da sua satisfação, que "[...] se relaciona com as expectativas atendidas. [...] é o sentimento em relação à compra. [...] pode resultar em um cliente tão fiel, que se torna muito difícil para outro profissional fazer negócios com ele" (FUTRELL, 2014, p. 388). Tendo em vista que fidelização de clientes consiste em um "[...] processo pelo qual um cliente se torna fiel, isto é, aquele cliente que sempre volta à empresa por estar satisfeito com os produtos ou serviços oferecidos" (BOGMANN, 2002, p. 21).

Ou seja, "sem satisfação, não há fidelização, retenção e lealdade. Como resultado, vem o churn, isto é, o cliente interrompe seu contrato com a empresa, trocando-a, em geral, 
por uma concorrente" (BARRETO; CRESCITELLI, 2012 apud SANTOS, 2015, p.50).

Um cliente satisfeito gera divulgação positiva, no entanto, quando acontece o contrario e o cliente fica com sentimento de insatisfação, isso faz com que a empresa gaste, e muito, para reconquistar esse publico perdido.

Assim "essa questão de satisfação é de extrema importância para a empresa. Afinal, apenas clientes satisfeitos ou encantados - ou seja, clientes que têm suas expectativas atendidas ou superadas, respectivamente podem se tornar fiéis" (SANTOS, 2015, p. 17). E com a finalidade de alcançar a satisfação dos clientes e obter a fidelização dos mesmos, as empresas podem utilizar alguns artifícios, sendo as ferramentas de marketing, grandes aliadas nesta busca. Por isso, devido a sua relevância para este fim, a próxima subseção é totalmente dedicada a expor ferramentas de marketing que podem ser utilizadas pelas organizações com a finalidade de fidelizar clientes.

\subsection{Ferramentas de Marketing}

Existe uma grande variedade de ferramentas de marketing que podem ser utilizadas pelas empresas com a finalidade de fidelizar clientes, neste artigo, optou-se por expor os mais populares, que são: pesquisa de mercado, endomarketing, CRM - Gestão de Relacionamento com o consumidor (Costumer Relationship Management), pós-venda e programa de fidelidade. Ferramentas estas, que serão abordadas em detalhes nos parágrafos seguintes.

Iniciando pela pesquisa de mercado que:

[...] é entendida por
muitos autores de
Marketing como sendo
qualquer esforço
planejado e organizado
para obter fatos e
conhecimentos novos que
facilitem o processo de
decisão de mercado. Ou,
ainda, a coleta, o registro
e a analise de todos os
fatos referentes aos
problemas relacionados à
transferência e venda de
mercadorias e serviços,
desde o produtor até o
consumidor. (COBRA,
2011, p.155).

Assim, essa ferramenta pode auxiliar na definição dos produtos/serviços oferecidos aos clientes a fim de minimizar cada vez mais a chance de erro na hora de tentar satisfazê-los, aumentando consideravelmente as chances de obter a fidelização dos mesmos.

Outra ferramenta que pode ser utilizada na fidelização de clientes é o endomarketing, que Matos (2014, p.127) define como sendo "um conjunto de ações de marketing institucional dirigidas para o publico interno. As ações que a empresa deve realizar para consolidar a sua boa imagem junto aos funcionários e seus familiares". Tornando os colaboradores motivados em trabalhar na empresa, se esforçando para atender os clientes, da melhor maneira possível, ato que contribui para fidelização destes. Tendo em vista que o endomarketing contribui para que o colaborador tenha uma imagem mais positiva da empresa e externe isso ao público externo.

Outra ferramenta que deve ser considerada é o CRM - Gestão de Relacionamento com o consumidor (Costumer Relationship Management) que Kotler e Armstrong (2015, p. 127) definem como sendo "softwares e ferramentas analíticas sofisticados, de empresas [...] que integram as informações dos clientes provenientes de todas as fontes, analisam-nas em profundidade e utilizam os resultados obtidos para desenvolver um sólido relacionamento com o cliente". Essas informações contribuem para que a empresa tenha maior conhecimento sobre seus consumidores, assim, tentando atender cada vez mais suas necessidades e desejos para que a fidelização aconteça, pois o CRM:

permite às empresas
prestar um excelente
serviço de atendimento ao
cliente em tempo real,
desenvolvendo um
relacionamento com cada
cliente preferencial por
meio do uso efetivo de
informações sobre contas
individuais. Com base no
conhecimento que têm de
cada cliente, as empresas
podem personalizar
ofertas de mercado,
serviços propagandas,
mensagens e mídia.
(KOTLER, 2005, p.35).


Satisfazendo melhor seus consumidores, por se basear nas informações colhidas, através de pesquisas, do que o consumidor compra, deseja e qual o seu perfil. Com essas analises, a empresa consegue organizar melhor suas propagandas e promoções otimizando o investimento para fidelização dos clientes.

Nesta mesma linha, de analisar o que o cliente quer e gosta, para fidelizá-lo tem-se outra ferramenta, o pós-venda. Que se pauta na premissa de que "o contato e o relacionamento com os clientes após a venda os fideliza e os transforma em clientes satisfeitos" (DEGEN, 2009, p.354). Considerando que, não é simplesmente vender determinado produto/serviço visando o lucro mas sim, buscar cada vez mais atender os desejos dos clientes, para fidelizá-lo.

Portanto, o pós-venda deve acontecer, efetivamente, após a realização da venda, pois nesse momento a organização saberá se o cliente ficou ou não satisfeito com sua compra, quanto antes esse procedimento for realizado, melhor para que haja mais efetividade, tendo em vista que Castro e Neves (2012, p.28) destacam que no pós venda:

\begin{abstract}
os vendedores continuam a enfatizar a satisfação do consumidor no período após a venda ter sido realizada. As atividades durante este tempo incluem reduzir as preocupações do cliente após a compra, assegurar a entrega dentro do prazo, instalação ou treinamento, prover acompanhamento ou manutenção, além de lidar com reclamações e questões. O objetivo é construir boa vontade e aumentar as chances de vendas futuras.
\end{abstract}

Esse procedimento de verificação da satisfação dos clientes, normalmente, funciona como uma ferramenta que liga a compra já realizada pelo cliente e uma compra futura, pois dependendo desse procedimento, o cliente poderá ou não voltar a comprar na empresa, isso consegue definir melhor seu perfil e fidelizar de uma maneira mais rápida e prática. Geralmente o pós-venda, é realizada através de telemarketing, porém pode-se utilizar também do sms onde as organizações "[...]consultam se $o$ atendimento foi bom, se permanece alguma dúvida ou se podem auxiliar [...] em alguma coisa a mais" (HILLMANN, 2013 , p. 42). Nesse tipo de procedimento, o cliente se sente importante para a organização aumentando as possibilidades de fidelização.

E por fim, a ultima ferramenta de marketing exposta nesta pesquisa, que é o programa de fidelidade ou fidelização. Na visão de Rocha (2009, p.199) "os programas de fidelização - que incluem presentes, promoções e centrais de atendimento - são um diferencial competitivo no momento da venda". Quando a empresa se utiliza de programas de fidelidade, pode-se entender que obtém vantagem em relação as outras empresas, pois, os consumidores consideram os benefícios que podem obter, contribuindo para sua fidelização.

Com base nisso Schiffman e Kanuk (2000 apud MOURA JUNIOR, 2008) definem que programas de fidelidade são ações voltadas para a criação de relacionamentos contínuos e duradouros com seus clientes e com isso, procurando estimular a lealdade e fidelidade em relação a seus produtos ofertados.

O uso desta ferramenta pelas empresas faz com que os consumidores se sintam importantes e também os motiva a continuar adquirindo produtos, pois, serão recompensados de alguma forma.

Portanto, não é possível classificar uma ou outra ferramenta de marketing como sendo mais importante ou melhor na fidelização de clientes, todas contribuem, pode-se dizer que são complementares e essenciais na tarefa de fidelizar a clientela.

\section{DISCUSSÃO}

Diante das transformações do mercado, que vem gerando o aumento constante das opções disponíveis, os consumidores vêm tornando-se cada dia mais exigentes e seletivos. Então, conquistá-los tem demandado novos esforços por parte das empresas, entre eles, destaca-se a necessidade de compreender seu comportamento de compra.

Compreensão esta que é fundamental para atração e principalmente, quando o objetivo é a fidelização, independente do tipo de produto que a empresa comercializa, seja bens duráveis, bens não duráveis ou serviços.

Pois todos estes segmentos apresentam características peculiares que refletem de alguma forma na vida do consumidor, principalmente os 
bens duráveis que geralmente demandam maior dispêndio de recursos, como é o caso das joalherias.

Diante disso, este artigo se propôs a identificar o comportamento de compra de consumidores do segmento de joalheria e ferramentas de marketing que esse tipo de negócio pode utilizar para fidelização dos clientes. E ao longo das seções, foi possível confirmar a hipótese inicial, de que existem diversos fatores que influenciam na decisão de compra do consumidor, alguns genéricos (comuns a maioria das decisões de compra) e outros específicos do segmento de joalherias e que existe diversas ferramentas de marketing que podem contribuir para fidelização deste publico.

Todas as analises e levantamentos permitiram concluir que o comportamento de compra dos consumidores do segmento de joalherias, é influenciado por fatores culturais, sociais, pessoais e psicológicos (genéricos) e por fatores específicos do segmento de joalherias, pois foi possível constatar que na maioria das vezes os consumidores destes produtos 0 adquirem para satisfazer sua vontade momentânea e, que não se importam em pagar valores altos por produtos personalizados, que propiciarão maior status.

Conclui-se também que, entre as ferramentas de marketing existentes e uteis a fidelização de clientes, as que mais se adéquam ao segmento de joalherias, considerando o comportamento desta categoria de consumidores, é a pesquisa de mercado, o endomarketing, o CRM, o pós-venda e o programa de fidelidade.

Portanto, conclui-se que o segmento de joalherias possui consumidores que apresentam características peculiares, em que é preciso ter um maior cuidado pois se trata de pessoas que prezam a qualidade do produto e também o atendimento.

\section{REFERÊNCIAS}

BOGMANN, I. M. Marketing de relacionamento: estratégias de fidelização e suas implicações financeiras. São Paulo: Livraria Nobel, 2002.

CASTARÉDE, J. O luxo: Os segredos dos produtos mais desejados do Mundo. São Paulo: Barcarolla, 2005.
CASTRO, L. T. ; NEVES, M. F. Administração de vendas: planejamento, estratégia e gestão. 1.ed. São Paulo : Atlas, 2012.

COBRA, M. Administração de marketing. 2. ed. 7. reimpr. São Paulo: Atlas, 2011.

DEGEN, R. J. O Empreendedor: empreender como opção de carreira. São Paulo: Pearson Prentice Hall, 2009.

FUTRELL, C. M. Vendas: fundamentos e novas práticas de gestão. 2. ed. São Paulo: Saraiva, 2014.

GALHANONE, R. F. O mercado do luxo: aspectos de marketing. São Paulo, 2005.

GIL, A. C. Como elaborar projetos de pesquisa. 5. ed. São Paulo: Atlas, 2010.

GOMES, R. Análise e interpretação de dados de pesquisa qualitativa. In: MINAYO, M. C. de S (Org.). Pesquisa social: teoria, método e criatividade. 26. ed. Petrópolis: Vozes, 2007. p. 79-107.

GUILGEN, C. A. de. ; FERRO, G. S. de. Design de jóias: cerâmica avançada e a prototipagem rápida na joalheria. [recurso eletrônico] Florianópolis, 2015. Acesso em 12 mar. 2017. Disponível em http://revista.ctai.senai.br/index.php/edicao01/a rticle/viewFile/541/392

HILLMANN, R. Administração de vendas, varejo e serviços. Curitiba: InterSaberes, 2013.

HONORATO, G. Conhecendo o marketing. Barueri, São Paulo: Manole, 2004.

MOURA JUNIOR, L. A. Programa de relacionamentos: uma avaliação Multi-Setorial Envolvendo Satisfação, Lealdade e Custos de Mudança Segundo a Percepção dos Clientes. Belo Horizonte: Universidade FUMEC, 2008. Disponível em:

http://www.fumec.br/anexos/cursos/mestrado/d issertacoes/completa/andre_luiz_de_moura_juni or.pdf. Acesso em: 01 maio 2017.

KERIN, R. A. et. al. Marketing. 8. ed. Porto Alegre: AMGH, 2011 
KOTLER, P.; ARMSTRONG, G. Princípios de marketing. 15. ed. São Paulo : Pearson Education do Brasil, 2015.

KOTLER, P. Administração de marketing: a edição do novo milênio. 10. ed. São Paulo: Prentice Hall, 2000.

KOTLER, P.; KELLER, K. L. Administração de marketing. 12. ed. São Paulo: Pearson Prentice Hall, 2006.

KOTLER, P. Marketing essencial: conceitos, estratégias e casos. São Paulo: Prentice Hall, 2005.

LAS CASAS, A. L. Administração de marketing: conceitos, planejamento e aplicações à realidade Brasileira. 1. ed. São Paulo: Atlas, 2006.

LIMEIRA, T. M. V. Comportamento do consumidor. 1. ed. São Paulo: Saraiva, 2008.

LIPOVETSKY, G.; ROUX, E. O Luxo eterno. da idade do sagrado ao tempo das marcas. Tradução de Maria Lúcia Machado. São Paulo: Companhia das Letras, 2005.

MASCARENHAS, S. A. Metodologia científica. São Paulo: Pearson Education do Brasil, 2012.

MATOS, G. G. de. Comunicação empresarial sem complicação: como facilitar a comunicação na empresa, pela via da cultura e do diálogo. 3 ed. Barueri, SP : Manole, 2014.

MERLO, E. M. Comportamento do consumidor. 1. ed. Rio de Janeiro : LTC, 2014.

OGDEN, J. R. ; CRESCITELLI, E. Comunicação integrada de marketing: conceitos, técnicas e práticas. 2 ed. São Paulo : Pearson Prentice Hall, 2007.

PAIXÃO, M. V. A influência do consumidor nas decisões de marketing. Curitiba: InterSaberes, 2012.

PASSARELLI, S. O Universo do luxo: marketing e estratégia para o mercado de bens e serviços de luxo. Barueri : Manole, 2010.
PETER, J. P. ; DONNELY JR, J. H. Introdução ao marketing: criando valor para clientes. 1 ed. São Paulo: Saraiva, 2013.

PETER, J. P. ; OLSON, J. C. Comportamento do consumidor e estratégias de marketing. [recurso eletrônico]. 8 ed. Porto Alegre: AMGH, 2010.

PETROCCHI, M. Hotelaria: planejamento e gestão. São Paulo: Pearson Prentice Hall, 2007.

ROCHA, L. C. Consumidor: como elaborar o seu perfil. Rio de Janeiro : LTC, 2009.

SAMARA, B. S.; MORSCH, M. A. Comportamento do consumidor: conceitos e casos. São Paulo: Pretince Hall, 2005.

SANTOS, A. S. dos. Marketing de relacionamento. São Paulo : Pearson Education do Brasil, 2015.

SHETH, J. N.; MITTAL, B. ; I. NEWMAN, B. Comportamento do cliente: Indo além do Comportamento do Consumidor. 1.ed. São Paulo: Atlas, 2001.

STRALIOTTO, L. M. Ciclos: estudo de casos de ecodesign de jóias. 2009. Dissertação (Mestrado em Design) - Programa de Pós-Graduação em Design, Universidade Federal do Rio Grande do Sul, Porto Alegre, 2009.

STREHLAU, S. O luxo falsificado e suas formas de consumo. Tese (Doutorado em Administração) -Escola de Administração de Empresas de São Paulo. Fundação Getúlio Vargas, 2004.

YANAZE, M. H.; MARKUS, K.; CARRILHO,K. Marketing fácil. 1. ed. São Paulo: Saraiva, 2012.

Recebido para publicação em 08/11/2017

Revisado em 04/03/2018

Aceito em 30/04/2019 